\title{
Bax mitochondrial relocation is linked to its phosphorylation and its interaction with $\mathrm{Bcl}-\mathrm{xL}$
}

\author{
David Garenne ${ }^{1,2}$, Thibaud T. Renault ${ }^{1,3}$, Stéphen Manon ${ }^{1, *}$ \\ ${ }^{1}$ Institut de Biochimie et de Génétique Cellulaires, UMR5095, CNRS \& Université de Bordeaux, CS61390, 146 Rue Léo Saignat, 33077 \\ Bordeaux, France. \\ ${ }^{2}$ Present address: INRA, UMR1332, 71 Avenue Edouard Bourlaud, 33882 Villenave d'Ornon, France. \\ ${ }^{3}$ Present address: Department of Regulation in Infection Biology, Charitéplatz 1, 10117 Berlin, Germany. \\ * Corresponding Author: \\ Stéphen Manon, E-mail: manon@ibgc.cnrs.fr
}

\begin{abstract}
The heterologous expression of Bax, and other $\mathrm{Bcl}-2$ family members, in the yeast Saccharomyces cerevisiae, has proved to be a valuable reporter system to investigate the molecular mechanisms underlying their interaction with mitochondria. By combining the co-expression of Bax and $\mathrm{Bcl}-\mathrm{xL}$ mutants with analyzes of their localization and interaction in mitochondria and post-mitochondrial supernatants, we showed that the ability of Bax and Bcl-xL to interact is dependent both on Bax phosphorylation - mimicked by a substitution S184D - and by Bax and Bcl-xL localization. This, and previous data, provide the molecular basis for a model of dynamic equilibrium for Bax localization and activation, regulated both by phosphorylation and Bcl-xL.
\end{abstract}

doi: $10.15698 /$ mic2016.12.547

Received originally: 20.07.2016;

in revised form: 14.08.2016,

Accepted 17.08.2016,

Published 05.12.2016.

Keywords: Bax, Bcl-xL, mitochondria, phosphorylation, cytochrome $c$ release, apoptosis, yeast (S.cerevisiae).

\section{INTRODUCTION}

The pro-apoptotic protein Bax is at the core of the process of mitochondria-dependent apoptosis in mammals. Bax is a member of the $\mathrm{Bcl}-2$ family, and contains $4 \mathrm{Bcl}-2$ homology domains $(\mathrm{BH} 1$ to $\mathrm{BH} 4)$ that are involved in its interaction with other Bcl-2 family members, including the antiapoptotic protein $\mathrm{BCl}-\mathrm{xL}$. In non-apoptotic cells, Bax is generally expressed at a low level, and remains essentially cytosolic, or weakly associated to mitochondria [1]([2-3] for reviews). Following an apoptotic stimulus, Bax is relocated to the mitochondria, and most specifically to the outer mitochondrial membrane. Bax can then be organized as dimers and oligomers that form a large-sized pore in this membrane. This pore favors the release of proteins together known as 'apoptogenic factors' that are released from the mitochondrial intermembrane space to the cytosol, and that confer their apoptotic characteristics to the cells. In addition to extended biochemical evidence, this model of a large sized pore formed with Bax molecules is also widely supported by electrophysiology [4-6], structural studies [7,8], biophysical approaches [9] and imaging data $[10,11]$.

As a central event in the apoptotic process, the translocation of Bax from the cytosol to the mitochondria has been the focus of a large number of studies, but is still not completely resolved. When located in the cytosol, Bax is a globular and mostly hydrophilic protein [12]. Bax can be activated through interacting with the $\mathrm{BH}$-domain of $\mathrm{BH} 3-$ only proteins, such as $\mathrm{tBid}$, Bim or Puma, that promotes major conformational changes to the protein [13]. Structural studies suggested that the interaction between Bax and a BH3-domain induced the formation of a head-to-tail dimer [7], that is able to lay flat on the mitochondrial membrane [8]. The association of several dimers is thought to form the oligomer that constitutes the pore [9]. This hypothesis has been supported by microscopy experiments showing the formation of a large-sized pore both in membranes and in mitochondria in situ $[10,11]$. However, this widely accepted model still contains a number of gray areas, including the role of the very hydrophobic C-terminal helix $\alpha 9$, that was absent from the structural data of the Bax dimer [7], and of which the actual role in Bax interaction with mitochondria remains unclear: indeed, its absence does not prevent the mitochondrial localization of Bax, nor Bax-induced outer membrane permeabilization $[14,15]$.

One intriguing issue is the role of the serine residue in position 184 (S184). It is one of the few polar residues in this otherwise hydrophobic $\alpha$-helix. The deletion of the S184 ( $\Delta$ S184) converts $\alpha 9$ into a bona fide membrane anchor, that is able to drive the constitutive mitochondrial localization of Bax [16]. Furthermore, the $\Delta S 184$ mutation 
prevented the regulation of mitochondrial Bax translocation by components of the TOM complex [17]. It has been established that $\mathrm{S} 184$ can be phosphorylated by different kinases, such as AKT $[18,19]$ and PKC [20]. This phosphorylation was shown to impair the mitochondrial relocation of Bax during apoptosis, that is consistent with the prosurvival function of AKT, including in cancer cells [21]. However, AKT has multiple cellular targets, and it is therefore difficult to identify precisely the actual role of Bax phosphorylation in the survival effects induced by AKT activation.

In recent experiments, we have co-expressed human Bax and AKT in yeast. Rather unexpectedly, we found that AKT increased both cellular and mitochondrial Bax content, and consequently increased the capacity of Bax to promote the release of cytochrome $c$ [22]. Also, substituted Bax mutants where S184 was replaced by non phosphorylatable Ala or Val residues, or by a phospho-mimetic Asp resi- due have been tested for their ability to interact with mitochondria [22,23]. Like wild-type Bax, the phosphomimetic mutant S184D had the same weak mitochondrial localization that had already been observed in mammalian cells [18]. However, this weak mitochondrial localization was paradoxically associated to a high capacity to release cytochrome $c$, suggesting that the mutation converted Bax into its active conformation [22,23]. Conversely, the nonphosphorylatable mutants S184A and S184V had a much higher mitochondrial localization. Because of this, they induced a stronger release of cytochrome $c$ than wild-type Bax. However, in spite of their much higher mitochondrial localization, they remained less active than the mutant S184D, suggesting that they adopted a poorly active conformation [22,23].

Bax translocation to mitochondria also depends on other proteins, such as the anti-apoptotic protein $\mathrm{Bcl}-\mathrm{xL}$. Under non-apoptotic conditions, Bcl-xL-overexpression
A

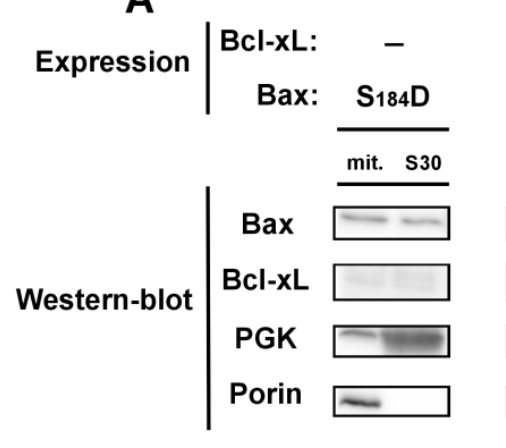

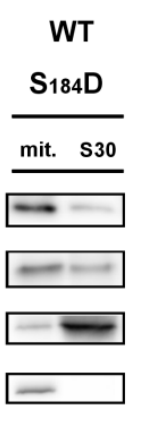

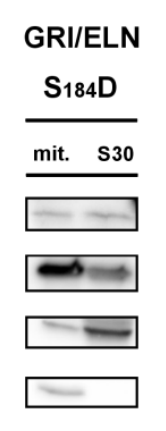

B

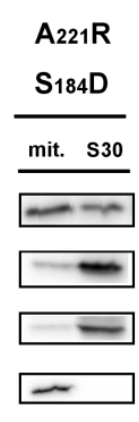

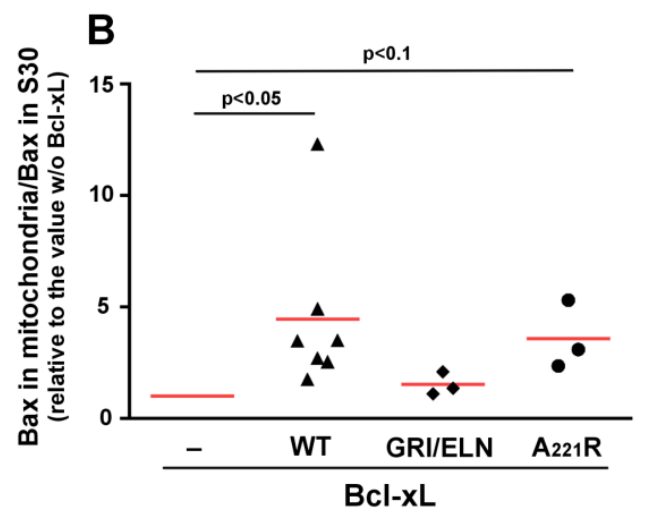

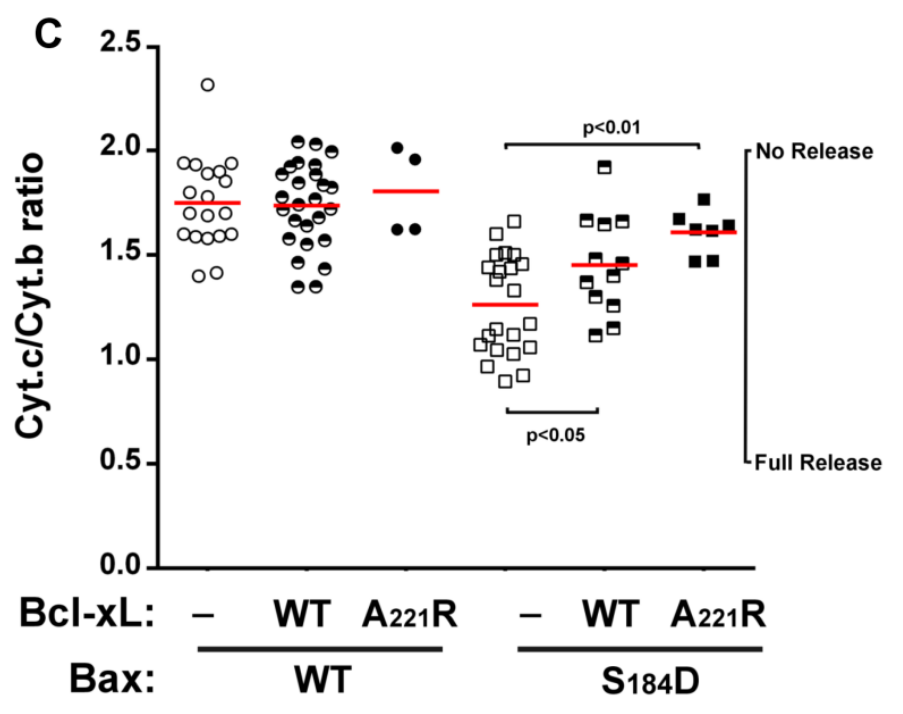

FIGURE 1: Effect of Bcl-xL on the localization and function of a Bax phosphomimetic mutant. Mitochondria (mit.) and post-mitochondrial supernatant (S30) were isolated from strains co-expressing Bax-S184D and wild-type Bcl-xL (WT), Bax interaction-deficient mutant carrying a triple mutation G138E/R139L/I140N (GRI/ELN), or a cytosolic mutant carrying a single mutation A221R (see Fig. 2). (A) Western-blot analysis of Bax and $\mathrm{Bcl}-\mathrm{xL}$ localization in both fractions. (B) Quantification of the ratio between mitochondrial and non-mitochondrial Bax. All the experiments were done in parallel to a control without $\mathrm{Bcl}-\mathrm{xL}$, for which the ratio was adjusted to 1 , as a reference. (C) Mitochondrial cytochrome $c$ content, measured as the ratio cytochrome $c / c y t o c h r o m e ~ b$ (unreleased cytochrome b serves as an internal control to the experiment). Each point represents an individual experiment. Data with wild-type Bax are given for a matter of comparison, and had been published previously $[22,24,34]$, except for the results with wild-type Bax and Bcl-xL-A221R. Red bars indicates the averages. $p$ values were calculated with an unpaired Student's test. 
increases the mitochondrial localization of Bax in parental mouse prolymphocytic cells FL5.12 or in human colorectal cancer cells HCT-116 [24]. A similar observation was made in yeast, where the co-expression of Bax and Bcl-xL induced a greater mitochondrial localization of Bax than when it was expressed alone [24]. This suggests that Bax translocation was related to intrinsic characteristics of the interaction between $\mathrm{Bax}$ and $\mathrm{Bcl}-\mathrm{xL}$, that were independent from the mammalian cellular context. Furthermore, when a truncated mutant $\mathrm{BCl}-\mathrm{xL} \Delta \mathrm{C}$ was co-expressed with $\mathrm{Bax}$, the stimulation of Bax mitochondrial localization was even greater than wilth full-length $\mathrm{Bcl}-\mathrm{xL}$, both in mammalian cells and in yeast [24]. Indeed, while Bcl-xL is able to retrotranslocate Bax from the mitochondria to the cytosol [25], Bcl-xL $\Delta \mathrm{C}$ lacks this ability $[24,26]$ and stimulates Bax activation [24]. These experiments and others [27] converge to support a model of dynamic equilibrium of Bax localization, that would be controlled, namely, by the phosphorylation of Bax and the interaction with $\mathrm{Bcl}-\mathrm{xL}$.

To further refine the model of regulation of Bax localization, we used yeast to investigate the dual role of Bax S184 phosphorylation and interaction with $\mathrm{Bcl}-\mathrm{xL}$ on $\mathrm{Bax}$ sub-cellular localization and activation. Bax mutants on S184 were co-expressed with different Bcl-xL mutants, and their localization, activity and ability to interact with each other in each compartment, mitochondrial and extramitochondrial.

\section{RESULTS AND DISCUSSION}

We previously reported that the phosphomimetic mutation S184D rendered Bax less stable in yeast, due to increased sensitivity to proteases: indeed, it was present at a lower level than BaxWT, but was restored at a normal level following the addition of the vacuolar protease inhibitor

A

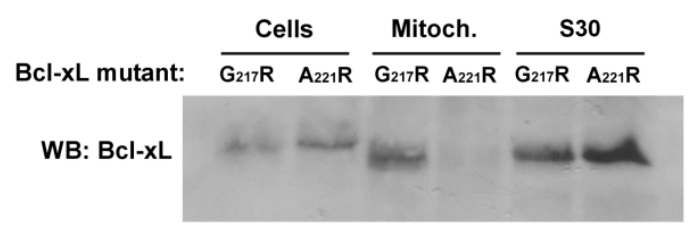

WB: PGK

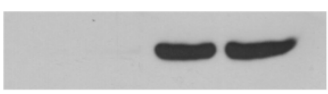

WB: Porin

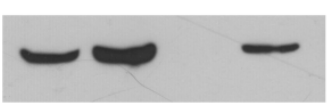

B

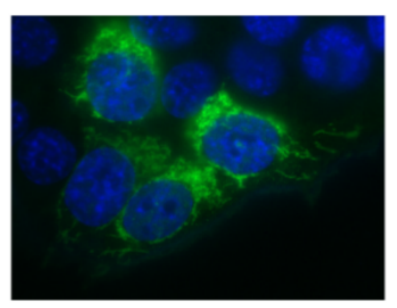

$+\mathrm{Bcl}-\mathrm{xL}$

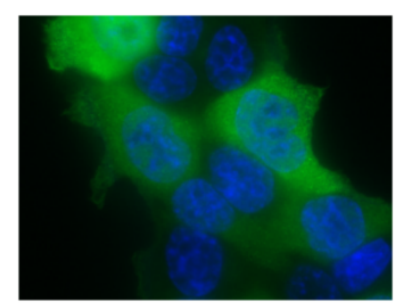

$+B c l-x L-A 221 R$
PMSF [22]. To eliminate possible differences caused by this different susceptibility to proteolysis, all the following experiments were done in a strain carrying a deletion of PEP4, that encodes the yeast homolog of mammalian Cathepsin $D$, that is the most abundant and active yeast protease.

$\Delta p e p 4$ yeast strains co-expressing mutants Bax-S184D

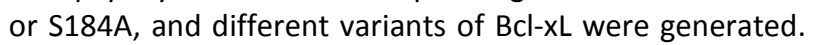
Mitochondria and post-mitochondrial supernatants were isolated, and the presence of Bax and Bcl-xL was probed, to evaluate the extent of Bax mitochondrial relocation.

Like previously reported for BaxWT [24], the coexpression of full-length $\mathrm{BCl}-\mathrm{xL}$ stimulated the mitochondrial localization of Bax-S184D (Fig. 1A, B). As expected, a mutant of $\mathrm{Bcl}-\mathrm{xL}$ carrying the triple substitution G138E/R139L/I140N impairing the interaction with Bax $[24,28]$, did not increase mitochondrial Bax content (Fig. 1A, $B)$. This unambiguously demonstrated that the physical interaction between $\mathrm{Bax}$ and $\mathrm{Bcl}-\mathrm{xL}$ was required for the stimulating effect of $\mathrm{Bcl}-\mathrm{xL}$ on $\mathrm{Bax}$ mitochondrial relocation.

The C-terminal $\alpha$-helix of $\mathrm{Bcl}-\mathrm{xL}$ is crucial for the mitochondrial localization of $\mathrm{Bcl}-\mathrm{xL}$, and its deletion makes $\mathrm{Bcl}-$ $x \mathrm{~L}$ lose its mitochondrial localization, both in yeast [29] and mammalian cells [30]. However, the drastic deletion of the whole helix may have dramatic consequences on the overall structure of the protein, with rather unpredictable consequences. Indeed, we have observed that, when expressed alone in yeast, truncated $\mathrm{BCl}-\mathrm{xL} \Delta \mathrm{C}$ had a weak but significant ability to release cytochrome $c$ [24], that may be related to a non-selective interaction with membranes, caused by the exposure of the core of the protein that is normally masked by the C-terminal $\alpha$-helix. To circumvent this possibility, we designed a mutant loosing the ability to reach mitochondria that was less drastically altered than the truncated protein. Residues at different positions in

FIGURE 2: Characterization of a cytosolic mutant of Bcl-xL. (A) Localization of two mutants of $\mathrm{BCl}-\mathrm{xL}$ carrying single substitutions in the $\mathrm{C}$-terminal $\alpha$-helix, following their expression in yeast. The mutant A221R was excluded from the mitochondrial fraction, opposite to the mutant G217R. (B) Localization of wild-type and A221R mutant of $\mathrm{Bcl}-\mathrm{xL}$ in HeLa cells. Cells were transfected with Bcl-xLexpressing plasmids and $\mathrm{Bcl}-\mathrm{xL}$ was detected by immunofluorescence as described previously [35]. Nuclei were counter-stained with DAPI. The mutant A221R displayed a diffuse cytosolic localization, opposite to the wild-type. 
the C-terminal hydrophobic $\alpha$-helix were substituted by large, positively charged residues ( $\mathrm{R}$ or $\mathrm{K}$ ), and the resulting mutants were tested for their capacity to be localized in the mitochondria. One mutant, carrying a substitution A221R, remained mostly cytosolic, both in yeast and human HeLa cells (Fig. 2).

When co-expressed with Bax-S184D, the mutant Bcl-xLA221R remained cytosolic but stimulated the mitochondrial localization of Bax-S184D, although to a lower extent than wild-type $\mathrm{BCl}-\mathrm{xL}$ (Fig. 1A, B). The fact that, although interacting with Bax-S184D, Bcl-xL-A221R remained mostly cytosolic, indicated that a transient interaction between both proteins might be sufficient to promote the conformational change leading to Bax mitochondrial relocation. A similar behaviour had been previously suggested for Bcl$\mathrm{xL} \Delta \mathrm{C}$, which increased the mitochondrial localization of Bax, although no stable interaction could be detected by coimmunoprecipitation [24].

Despite its weak mitochondrial localization, Bax-S184D has been shown to induce a large release of cytochrome $c$ [22,23] (Fig. 1C). This shows that, even though a small amount of Bax-S184D can reach the mitochondrial membrane, it displays a very high capacity to permeabilize this membrane. On the other hand, it has been shown that AKT-dependent phosphorylation of Bax on S184 prevented apoptosis in human neutrophils [18]. It can therefore be hypothesized that, under those conditions, additional factors were present, that impaired the capacity of phosphorylated Bax to reach and/or to permeabilize mitochondria.

Obvious candidates for this effect are anti-apoptotic proteins, such as Bcl-xL. Consequently, we investigated if the capacity of Bax-S184D to permeabilize mitochondria was or not sensitive to full-length $B c l-x L$ and to its cytosolic mutant Bcl-xL-A221R. As expected, cytochrome $c$ release induced by Bax-S184D was partly inhibited by the coexpression of wild-type $\mathrm{BCl}-\mathrm{xL}$ (Fig. $1 \mathrm{C}$ ), that is localized at the mitochondria (Fig. 1A, B). It could reasonably be expected that the largely cytosolic localization of $\mathrm{Bcl}-\mathrm{xL}-$ A221R (Fig. 1A, B) would impair its ability to inhibit Bax. However, in striking contradiction with this prediction, and despite the fact that it stimulated the mitochondrial localization of Bax-S184D (Fig. 1A, B), we observed that Bcl-xL$A 221 R$ was able to inhibit Bax-S184D at least as efficiently as wild-type $\mathrm{Bcl}-\mathrm{xL}$ (Fig. 1C).

Although they are not perfect homologs, the yeast kinase Sch9p has similar functions as mammalian AKT [31]. It is therefore possible that the expression of BaxWT in yeast would result in a partial phosphorylation of S184. We therefore expressed a non-phosphorylatable mutant BaxS184A. This mutant had been found to have a constitutive
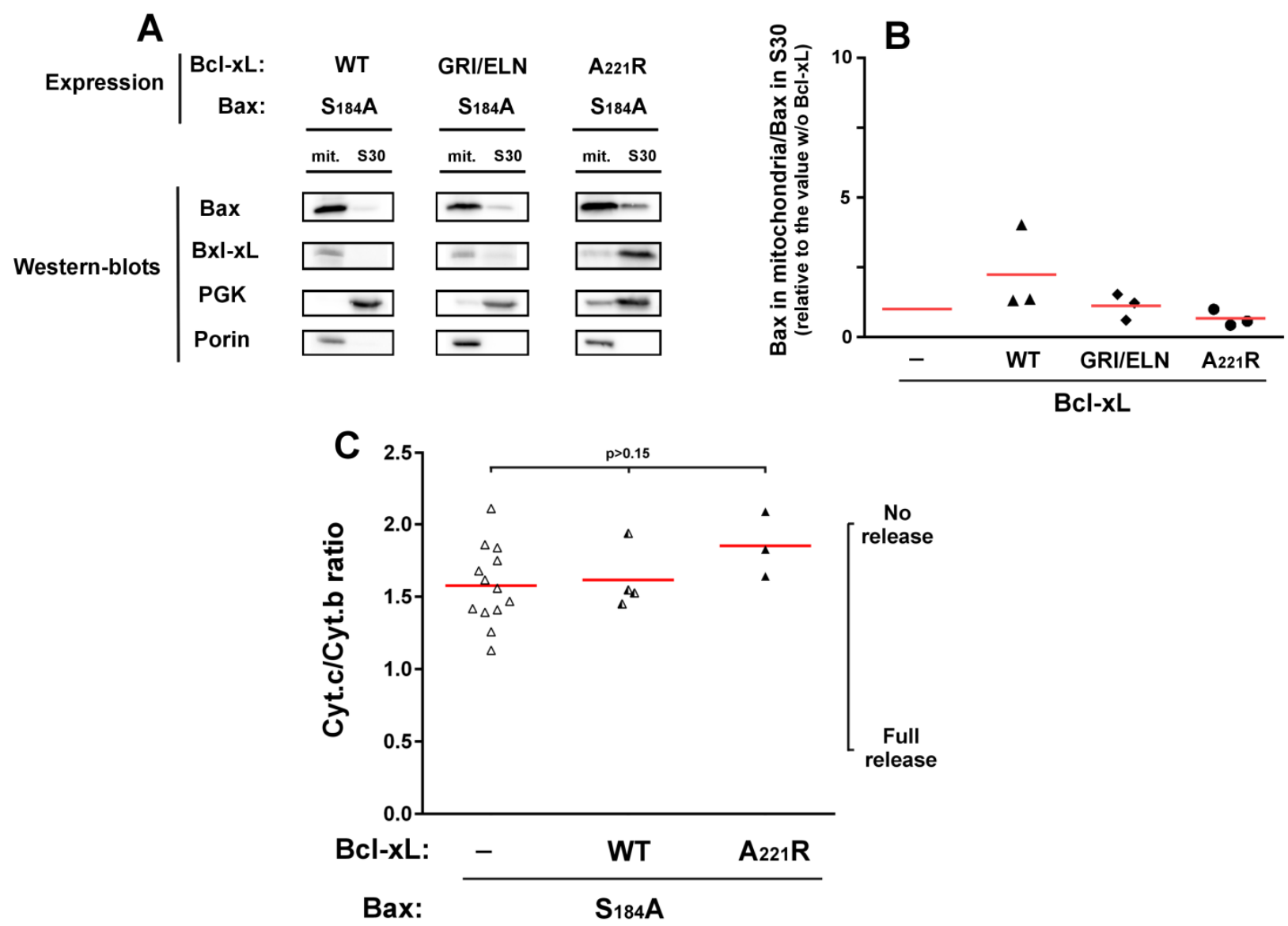

FIGURE 3: Effect of Bcl-xL on the localization and function of a non-phosphorylatable Bax mutant. Same conditions as in Figure 1, with BaxS184A instead of Bax-S184D. 
mitochondrial localization both in neutrophils [18] and in yeast $[22,23]$. We observed that this mitochondrial localization was insensitive to the presence of $\mathrm{Bcl}-\mathrm{xL}$, whichever mutant was used (wild-type, deficient for Bax-interaction, or cytosolic) (Fig. 3A, B). Despite this constitutive mitochondrial localization, and opposite to mutant Bax-S184D, Bax-S184A exhibited a weak capacity to release cytochrome $c$ (Fig. 3C). Furthermore, this weak ability to release cytochrome $c$ was not significantly inhibited by $\mathrm{Bcl}-\mathrm{xL}$ (Fig. $3 C$ ), indicating that it was most likely related to the presence of a high amount of protein in the mitochondrial membrane, rather than to a bona fide specific activity.

We next investigated if the differential inhibition of Bax-S184D and Bax-S184A by Bcl-xL reflected a different degree of interaction between cytosolic and mitochondrial Bax. First, BaxWT and Bcl-xL were co-expressed, Bax was immunoprecipitated from the mitochondrial and postmitochondrial fractions, and the presence of $\mathrm{Bcl}-\mathrm{xL}$ was measured in the immunoprecipitate (Fig. 4A). We observed that the low amount of Bax present in mitochondria could immunoprecipitate a large amount of $\mathrm{BCl}-\mathrm{xL}$. Conversely, the large amount of Bax present in the post-mitochondrial supernatant could only precipitate traces of $\mathrm{Bcl}-\mathrm{xL}$. As a negative control, no co-immunoprecipitation was observed between BaxWT and the interaction-deficient mutant BclxL G138E/R139L/I140N.

The same experiment was done with the mutant BaxS184A and $\mathrm{Bcl}-\mathrm{xL}$. In line with the fact that $\mathrm{Bcl}-\mathrm{xL}$ did not inhibit the moderate cytochrome $c$ release induced by BaxS184A, no significant interaction could be detected between Bax-S184A and Bcl-xL in mitochondria, even though both proteins are abundantly present in this compartment.

The same experiment was done with the mutant BaxS184D and Bcl-xL. Some weak interaction was found in mitochondria (compare with the total absence of signal in the control experiment with the mutant $\mathrm{Bcl}-\mathrm{xL}$ G138E/R139L/I140N), while, in spite of the high content of both proteins, no interaction could be depicted in the postmitochondrial supernatant.

In a previous paper, we used the $\mathrm{BH} 3-$ mimetic molecule ABT-737 to reveal the priming of Bax by $\mathrm{BCl}-\mathrm{xL}$ in yeast [24], in an assay that was based on a similar experiment done on pure recombinant proteins [32]. We had found that, in the presence of $\mathrm{Bcl}-\mathrm{xL}, \mathrm{ABT}-737$ activated BaxWT while it was without effect on BaxWT expressed alone, which was interpreted as the fact that the interaction of Bax with Bcl-xL favored the active conformation of Bax. We replicated the experiment with $\mathrm{BaxWT} / \mathrm{Bcl}-\mathrm{xL}$, but not with Bax-S184D/Bcl-xL (Fig. 4B), that was in line with the hypothesis that Bax-S184D is already under an active conformation. However, we observed an ambiguous result with Bax-S184A/Bcl-xL, suggesting that this mutant might still be converted to an active conformation, although less easily than BaxWT, that is in line with the observation above that it interacted loosely with $\mathrm{Bcl}-\mathrm{xL}$ (Fig. 4A).
Taken together, data reported herein suggest that the phosphorylation status of Bax S184 residue is crucial to determine its ability to relocate at the outer mitochondrial membrane, to permeabilize this membrane, and to be inhibited by Bcl-xL. A tricky aspect of Bax properties is that, when considered separately, they may have contradictory outcomes on the final activity of Bax, i.e. on its ability to promote the release of cytochrome $c$ (and possibly of other factors) and to trigger apoptosis. Indeed, mimicking the phosphorylation of S184, that may occur following the activation of the survival (i.e. anti-apoptotic) protein kinase $\mathrm{AKT}$, has distinct consequences, depending on the presence of Bcl-xL. In the absence of Bcl-xL, Bax-S184D had a strong activity that is not abolished by its weak mitochondrial localization. This resulted in a high capacity to permeabilize mitochondria. However, when $\mathrm{Bcl}-\mathrm{xL}$ is also expressed, a condition that most likely reflects the situation in tumoral cells, Bax-S184D is both relocated to the mitochondria and bound and inhibited by Bcl-xL. We have previously demonstrated that, in mammalian cells, this situation put the cells on the edge of entering apoptosis, simply by breaking the interaction between Bax and $\mathrm{Bcl}-\mathrm{xL}$ with, for example, a BH3-mimetic drug, that mimics the action of a BH3-only protein, such as Bim, on prolymphocytes [24]. Alternatively, if the interaction between $\mathrm{Bax}$ and $\mathrm{BCl}-\mathrm{xL}$ is maintained, due to the absence/inactivation of BH3-only proteins, Bax can be retrotranslocated to the cytosol (Fig. 5).

Another aspect to consider is the higher turnover of Bax-S184D (compared to BaxWT) that reflects a greater protease sensitivity [22]. In the present study, we have reduced the influence of this parameter by working in a $\Delta p e p 4$ strain, allowing us to detect the greater intrinsic activity of this mutant, that might not have been possible in situations where this mutant was quickly degraded. Furthermore, $\mathrm{Bcl}-\mathrm{xL}$ protects Bax-S184D against proteases, by masking proteolytic sites [22] and/or driving Bax to the mitochondrial outer membrane [24], a process that may also happen in mammalian cells [24] and be extended to $\mathrm{Bcl}-2$ [33]. This might also explain why Bax phosphorylated on S184 is not easily detectable.

The introduction of a negative charge in an overall hydrophobic $\alpha$-helix is expected to impair the membrane insertion of this helix. It is therefore somewhat counterintuitive that Bax-S184D is able to release cytochrome $c$ (Fig. 1). However, the recent models of Bax pore do not any give indication about the localization of $\alpha 9$ (because it is absent from the resolved structure) and it might be speculated that it could be localized on the walls of the pore, with the negative charge facing the hole, thus facilitating the passage of positively charged cytochrome $c$. As a matter of fact, we have reported that a mutant carrying a mutation T174D, located on the same side of the helix as S184, had a cytochrome $c$ release activity when expressed in yeast [34]. 

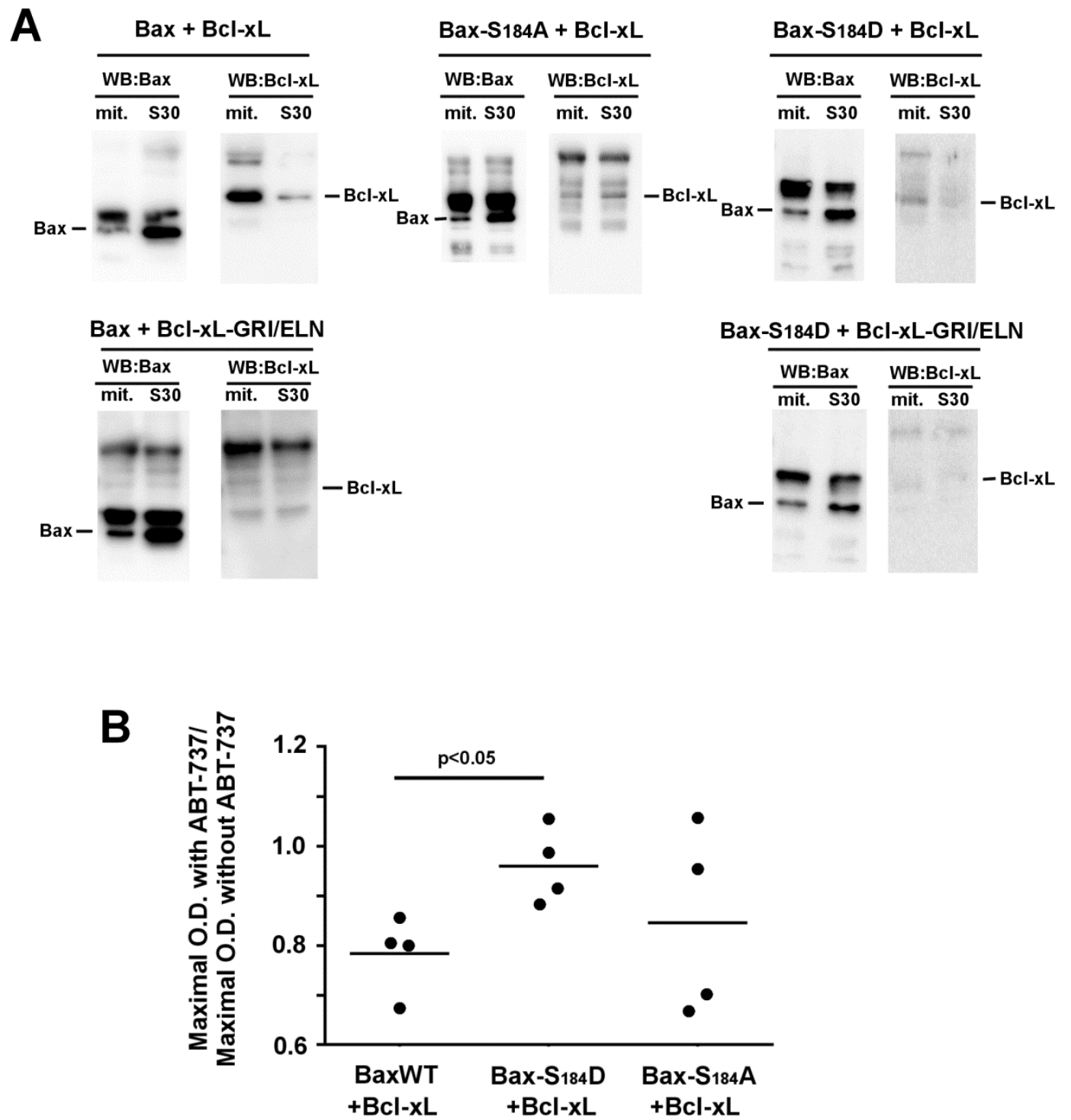

FIGURE 4: Interaction between Bax and Bcl-xL. (A) Immunoprecipitation experiments were done on mitochondria and S30 fractions from cells expressing indicated Bax mutants with or without Bcl-xL or Bcl-xL GRI/ELN, as a negative control. $2 \mathrm{mg}$ proteins of each fraction were immunoprecipitated with an anti-Bax antibody (2D2, Sigma). Blots are representative of experiments that have been done 5 times for $\mathrm{Bax} / \mathrm{Bcl}-\mathrm{xL}$, 3 times for Bax-S184A/Bcl-xL and Bax-S184D/Bcl-xL, and twice for negative controls with Bcl-xL-GRI/ELN. Inputs were omitted for clarity and can be seen in Fig. S1. (Left) (Top) The IP against Bax showed the interaction with Bcl-xL only in the mitochondrial fraction. (Left) (Bottom) and (Right) (Bottom) The absence of signal when BaxWT or Bax-S184D were co-expressed with Bcl-xL GRI/ELN evidenced the specificity of the signal. (Middle) Bax-S184A was co-expressed with wild-type Bcl-xL. The interaction was very weak, and similar in both fractions. (Right) Bax-S184D was co-expressed with wild-type Bcl-xL. Like for BaxWT, the interaction with Bcl-xL occurred mostly in the mitochondrial fraction. (B) Yeast cells co-expressing the three variants of Bax with Bcl-xL were grown in a small volume of SD-Lactate medium (2 mL) at the same O.D.600nm (0.2). 1\% galactose was added to induce the expression of both proteins. 2 hours later, each culture was shared in half, and $20 \mu \mathrm{M}$ ABT-737 (or an equivalent volume of DMSO) was added. The O.D.600nm was measured after 24 hours and the ratios between the presence and the absence of ABT-737 were plotted. The ratios did not change significantly after 36 hours.

Mimicking the total absence of phosphorylation on S184, has completely different consequences: Bax-S184A has a constitutive mitochondrial localization, is poorly active, and both its localization and activity are insensitive to Bcl-xL. It should be noted, however, that Bax-S184A and Bax-S184D are not mirroring each other: both are more efficient than wild-type Bax to induce cytochrome $c$ release, the former because of its higher mitochondrial content, the later because of its higher intrinsic activity. This may indicate that non-phosphorylated Bax can be located at the outer mitochondrial membrane, independently from the presence of $\mathrm{Bcl}-\mathrm{xL}$ [22], but can only be fully activated if Bax is phosphorylated, so that the whole previous cycle can occur (Fig. 5). This intricate succession of events, combining Bax phosphorylation and dephosphorylation, mitochondrial relocation and retrotranslocation, and binding and release to $\mathrm{BCl}-\mathrm{xL}$ (Fig. 5), may ensure a finely tuned regulation of cell death. 


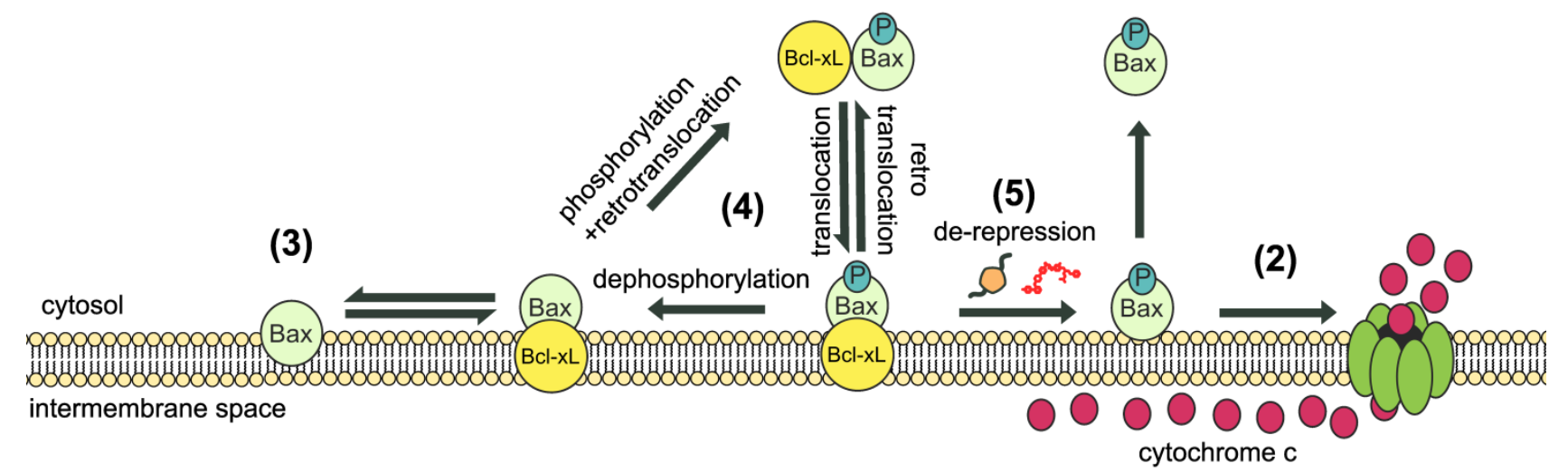

FIGURE 5: Model of dynamic equilibrium for Bax localization and activation. The model is based on data from the present paper, and from previous papers on the yeast model [20,22], and on mammalian cells $[24,26,27]$. (1) When Bax is phosphorylated on S184, it is spontaneously mostly located in the cytosol. However, the small fraction that remains in the mitochondrial membrane is able to oligomerize to form a pore that promotes the release of cytochrome $c$ (2). (3) When Bax is not phosphorylated, it is spontaneously mostly located in the mitochondrial membrane, but is unable to oligomerize to form the pore. (4) In the presence of Bcl-xL, phosphorylated Bax and Bcl-xL are conveyed together to the membrane where the high stability of the interaction prevents the activation of Bax. Although the process is reversible through retrotranslocation, the system is favored towards Bax mitochondrial localization through the possible dephosphorylation of Bax. (5) Conversely, in the presence of derepressors of the interaction between Bax and Bcl-xL (BH3-only proteins, such as Bim, or BH3-mimetic molecules, such as ABT-737), Bax is able to form a pore with great efficiency because it is already present in great amount in the membrane (see the discussion in [24]).

\section{MATERIALS AND METHODS}

The Saccharomyces cerevisiae strain W303-1A (mat a; ade2-1; his3-11,15; leu2-3,112; trp1-1; ura3-1) was carrying a deletion of the gene PEP4, of which the entire open reading frame was replaced by the gene $\operatorname{kanMX} 4$. This was done to prevent the degradation of the Bax-S184D mutant [22]. This strain W3031A $\triangle$ pep4::kanMX4 was transformed or co-transformed with PYES3 and pYES2 plasmids that drove the expression of Bax and $\mathrm{BCl}-\mathrm{xL}$ mutants, respectively. For Bax, the CDNA encoding the complete human Bax (without additional tag) was modified to fit the yeast codon bias. Bax and $\mathrm{Bcl}-\mathrm{xL}$ were cloned downstream the GAL1/10 promoter. Mutations were introduced by the Quickchange method, and the complete sequence of Bax and Bcl-xL was checked for the absence of unwanted mutations.

Yeast cells were grown aerobically in a minimal medium (0.17\% Yeast Nitrogen Base, 0.5\% ammonium sulfate, $0.1 \%$ potassium phosphate, $0.2 \%$ Drop-Mix, 2\% DL-Lactate, $0.01 \%$ auxotrophic requirements, $\mathrm{pH} 5.5$ ) until early exponential growth phase (O.D. ${ }_{550 \mathrm{~nm}}=0.5$ ). $1 \%$ galactose was added to induce the expression of $\mathrm{Bax}$ and $\mathrm{BCl}-\mathrm{xL}$ for 14 hours. At this stage, the O.D. of yeast cultures were in the range $1 \sim 1.5$. Mitochondria and post-mitochondrial supernatants (S30) were isolated from spheroplasts, like published previously [34]. Most experiments have been done immediately on freshly isolated fractions, but some additional experiments have been done on mitochondrial suspension frozen as small beads in liquid nitrogen.

For measuring $\mathrm{Bax}$ and $\mathrm{Bcl}-\mathrm{xL}$ content, $0.5 \mathrm{mg}$ proteins from mitochondria and $\mathrm{S} 30$ have been precipitated with $0.3 \mathrm{M}$ trichloroacetic acid, washed twice with acetone, and solubilized in Laemmli buffer. $100 \mu \mathrm{g}$ of proteins were separated by SDS-PAGE (12.5\% acrylamide), blotted on PVDF, and revealed with antibodies against $\mathrm{Bax}, \mathrm{Bcl}-\mathrm{xL}$, Porin and PGK (as mitochondrial and cytosolic markers, respectively).

For immunoprecipitation, $2 \mathrm{mg}$ proteins from mitochondria and S30 fractions were solubilized for 30 minutes in 0.5 $\mathrm{mL}$ of 1 X IP50 buffer from Sigma, then incubated overnight with $2 \mu \mathrm{g}$ anti-Bax antibody (2D2, Sigma), and 4 additional hours with protein $50 \mu \mathrm{L} \mathrm{G}$-sepharose beads (Sigma). Beads were washed 4 times with 1 X IP50 buffer and twice with $0.1 \mathrm{X}$ IP50 buffer, and incubated with $20 \mu \mathrm{L}$ Laemmli buffer, before SDS-PAGE and Western-blotting.

Cytochromes content of mitochondria was measured by differential redox spectrophotometry, as described previously [24].

Antibodies used were as follows: rabbit polyclonal antihuman Bax N20 antibody (Santa-Cruz, 1/5,000e), mouse monoclonal anti-human Bcl-xL antibody (BD Transduction Laboratories, 1/5,000e), mouse monoclonal anti-yeast porin (Novex, $1 / 40,000$ ), mouse monoclonal anti-yeast PGK (Novex, $1 / 10,000 e)$, HRP-coupled anti-rabbit or mouse IgG (Jackson Laboratories, 1/10,000e).

Western-blot and immunoprecipitation experiments were done a minimum of 5 times, on mitochondria and S30 fractions done simultaneously on strains relevant for direct comparison (for example, 3 strains co-expressing one Bax mutant with 3 mutants of $\mathrm{Bcl}-\mathrm{xL}$, or 3 strains co-expressing $3 \mathrm{Bax}$ mutants with the same mutant of $\mathrm{Bcl}-\mathrm{xL}$ ). ABT-737 was from $\mathrm{Ab}$ bott Labs and was dissolved in cell culture-grade DMSO.

\section{AKNOWLEDGEMENTS}

This work was supported by the Centre National de la Recherche Scientifique (UMR5095), the Université of Bordeaux, and the Agence Nationale de la Recherche (Project 'Phosbax'). 


\section{SUPPLEMENTAL MATERIAL}

All supplemental data for this article are available online at www.microbialcell.com.

\section{CONFLICT OF INTEREST}

The authors declare no conflict of interest.

\section{COPYRIGHT}

(C) 2016 Garenne et al. This is an open-access article released under the terms of the Creative Commons Attribution (CC BY) license, which allows the unrestricted use, distribution, and reproduction in any medium, provided the original author and source are acknowledged.

\section{REFERENCES}

1. Wolter KG, Hsu YT, Smith CL, Nechushtan A, Xi XG, and Youle RJ (1997). Movement of Bax from the cytosol to mitochondria during apoptosis. J Cell Biol 139(5):1281-1292.

2. Renault TT and Manon S (2011). Bax: Addressed to kill. Biochimie 93(9):1379-1391.

3. Westphal D, Dewson G, Czabotar PE and Kluck RM (2011). Molecular biology of Bax and Bak activation and action. Biochim Biophys Acta 1813(4):521-531.

4. Pavlov EV, Priault M, Pietkiewicz D, Cheng EH, Antonsson B, Manon S, Korsmeyer SJ, Mannella CA and Kinnally KW (2001). A novel, high conductance channel of mitochondria linked to apoptosis in mammalian cells and Bax expression in yeast. J Cell Biol 155(5):725-731.

5. Dejean LM, Martinez-Caballero S, Guo L, Hughes C, Teijido O, Ducret T, Ichas F, Korsmeyer SJ, Antonsson B, Jonas EA and Kinnally KW (2005). Oligomeric Bax is a component of the putative cytochrome $c$ release channel MAC, mitochondrial apoptosis-induced channel. Mol Biol Cell 16(5):2424-2432.

6. Martinez-Caballero S, Dejean LM, Kinnally MS, Oh KJ, Mannella CA and Kinnally KW (2009). Assembly of the mitochondrial apoptosisinduced channel, MAC. J Biol Chem 284(18):12235-12245.

7. Czabotar PE, Westphal D, Dewson G, Ma S, Hockings C, Fairlie WD Lee EF, Yao S, Robin AY, Smith BJ, Huang DC, Kluck RM, Adams JM and Colman PM (2013). Bax crystal structures reveal how $\mathrm{BH} 3$ domains activate Bax and nucleate its oligomerization to induce apoptosis. Cell 152(3):519-531.

8. Westphal D, Dewson G, Menard M, Frederick P, lyer S, Bartolo R, Gibson L, Czabotar PE, Smith BJ, Adams JM, Kluck RM (2014). Apoptotic pore formation is associated with in-plane insertion of Bak or Bax central helices into the mitochondrial outer membrane. Proc Natl Acad Sci U S A 111(39):E4076-E4085.

9. Subburaj $Y$, Cosentino K, Axmann M, Pedrueza-Villalmanzo E, Hermann E, Bleicken S, Spatz J, García-Sáez AJ (2015). Bax monomers form dimer units in the membrane that further self-assemble into multiple oligomeric species. Nat Commun 6:8042.

10. Salvador-Gallego R, Mund M, Cosentino K, Schneider J, Unsay J, Schraermeyer U, Engelhardt J, Ries J, and García-Sáez AJ (2016). Bax assembly into rings and arcs in apoptotic mitochondria is linked to membrane pores. EMBO J 35(4):389-401.

11. Große L, Wurm CA, Brüser C, Neumann D, Jans DC, and Jakobs $S$ (2016). Bax assembles into large ring-like structures remodeling the mitochondrial outer membrane in apoptosis. EMBO J 35(4):402-413.
Please cite this article as: David Garenne, Thibaud T. Renault, Stéphen Manon (2016). Bax mitochondrial relocation is linked to its phosphorylation and its interaction with Bcl-xL. Microbial Cell 3(12): 597-605. doi: 10.15698/mic2016.12.547

12. Suzuki M, Youle RJ, and Tjandra N (2000). Structure of Bax: coregulation of dimer formation and intracellular localization. Cell 103(4):645-654.

13. Willis SN, Fletcher JI, Kaufmann T, van Delft MF, Chen L, Czabotar $P E$, lerino $H$, Lee EF, Fairlie WD, Bouillet $P$, Strasser A, Kluck RM, Adams JM, and Huang DC (2007). Apoptosis initiated when BH3 ligands engage multiple $\mathrm{Bcl}-2$ homologs, not $\mathrm{Bax}$ or Bak. Science 315(5813):856-859.

14. Cartron PF, Priault M, Oliver L, Meflah K, Manon S, and Vallette FM (2003). The N-terminal end of Bax contains a mitochondrial-targeting signal. J Biol Chem 278(13):11633-11641.

15. Priault M, Cartron PF, Camougrand N, Antonsson B, Vallette FM, and Manon S (2003). Investigation of the role of the C-terminus of Bax and of tc-Bid on Bax interaction with yeast mitochondria. Cell Death Differ 10(9):1068-1077.

16. Nechushtan A, Smith CL, Hsu YT, and Youle RJ (1999). Conformation of the Bax C-terminus regulates subcellular location and cell death. EMBO J 18(9):2330-2341.

17. Bellot G, Cartron PF, Er E, Oliver L, Juin P, Armstrong LC, Bornstein $P$, Mihara K, Manon S, and Vallette FM (2007). TOM22, a core component of the mitochondria outer membrane protein translocation pore, is a mitochondrial receptor for the proapoptotic protein Bax. Cell Death Differ 14(4):785-794.

18. Gardai SJ, Hildeman DA, Frankel SK, Whitlock BB, Frasch SC, Borregaard N, Marrack P, Bratton DL, and Henson PM (2004). Phosphorylation of Bax Ser184 by Akt regulates its activity and apoptosis in neutrophils. J Biol Chem 279(20):21085-21095.

19. Xin $M$ and Deng $X$ (2005). Nicotine inactivation of the proapoptotic function of Bax through phosphorylation. J Biol Chem 280(11):1078110789.

20. Xin M, Gao F, May WS, Flagg T and Deng X (2007). Protein kinase Czeta abrogates the proapoptotic function of Bax through phosphorylation. J Biol Chem 282(29):21268-21277.

21. Cheung M and Testa JR (2013). Diverse mechanisms of AKT pathway activation in human malignancy. Curr Cancer Drug Targets 13(3):234-44.

22. Simonyan L, Renault TT, da Costa Novais MJ, Sousa MJ, Côrte-Real M, Camougrand N, Gonzalez C, and Manon S (2016). Regulation of Bax/mitochondria interaction by AKT. FEBS Lett 590(1):13-21.

23. Arokium H, Ouerfelli H, Velours G, Camougrand N, Vallette FM and Manon S (2007). Substitutions of potentially phosphorylatable serine residues of Bax reveal how they may regulate its interaction with mitochondria. J Biol Chem 282(48):35104-35112. 
24. Renault TT, Teijido O, Missire F, Ganesan YT, Velours G, Arokium H, Beaumatin $F$, Llanos $R$, Athané $A$, Camougrand $N$, Priault $M, A n-$ tonsson B, Dejean LM, and Manon S (2015). Bcl-xL stimulates Bax relocation to mitochondria and primes cells to $A B T-737$. Int J Biochem Cell Biol 64:136-146.

25. Edlich F, Banerjee S, Suzuki M, Cleland MM, Arnoult D, Wang C, Neutzner A, Tjandra $\mathrm{N}$ and Youle RJ (2011). $\mathrm{Bcl}-\mathrm{x}(\mathrm{L})$ retrotranslocates Bax from the mitochondria into the cytosol. Cell 145(1):104-116.

26. Todt F, Cakir Z, Reichenbach F, Youle RJ and Edlich F (2013). The Cterminal helix of $\mathrm{Bcl}-\mathrm{x}(\mathrm{L})$ mediates $\mathrm{Bax}$ retrotranslocation from the mitochondria. Cell Death Differ 20(2):333-342.

27. Schellenberg B1, Wang $P$, Keeble JA, Rodriguez-Enriquez $R$, Walker $\mathrm{S}$, Owens TW, Foster F, Tanianis-Hughes J, Brennan K, Streuli $\mathrm{CH}$ and Gilmore AP (2013). Bax exists in a dynamic equilibrium between the cytosol and mitochondria to control apoptotic priming. Mol Cell 49(5):959-971.

28. Ottilie S, Diaz JL, Chang J, Wilson G, Tuffo KM, Weeks S, McConnell $\mathrm{M}$, Wang $\mathrm{Y}$, Oltersdorf $\mathrm{T}$, and Fritz LC (1997). Structural and functional complementation of an inactive Bcl-2 mutant by Bax truncation. J Biol Chem 272 (49): 16955-16961.

29. Priault M, Camougrand N, Chaudhuri B and Manon S (1999). Role of the $\mathrm{C}$-terminal domain of $\mathrm{Bax}$ and $\mathrm{BCl}-\mathrm{XL}$ in their localization and function in yeast cells. FEBS Lett 443(2):225-228.
30. Kaufmann T, Schlipf S, Sanz J, Neubert K, Stein R and Borner C (2003). Characterization of the signal that directs $\mathrm{Bcl}-\mathrm{x}(\mathrm{L})$, but not $\mathrm{Bcl}-$ 2, to the mitochondrial outer membrane. J Cell Biol 160(1):53-64.

31. Morano KA and Thiele DJ (1999). The Sch9 protein kinase regulates Hsp90 chaperone complex signal transduction activity in vivo. EMBO J 18(21):5953-5962.

32. Gautier F, Guillemin Y, Cartron PF, Gallenne T, Cauquil N, Le Diguarher T, Casara P, Vallette FM, Manon S, Hickman JA, Geneste O, Juin $P$. (2011) Bax activation by engagement with, then release from, the BH3 binding site of Bcl-xL. Mol Cell Biol 31(4):832-844.

33. Teijido O, Dejean L (2010). Upregulation of Bcl2 inhibits apoptosisdriven $B A X$ insertion but favors $B A X$ relocalization in mitochondria. FEBS Lett 584(15):3305-10.

34. Arokium H, Camougrand N, Vallette FM, Manon S (2004). Studies of the interaction of substituted mutants of BAX with yeast mitochondria reveal that the $\mathrm{C}$-terminal hydrophobic alpha-helix is a second ART sequence and plays a role in the interaction with anti-apoptotic BCL-xL. J Biol Chem 279(50):52566-73.

35. Beaumatin F, El Dhaybi M, Lasserre JP, Salin B, Moyer MP, Verdier M, Manon S, Priault M (2016) N52 monodeamidated Bcl xL shows impaired oncogenic properties in vivo and in vitro. Oncotarget 7(13):17129-17143. 